\section{Entrevista con}

Francisco "Pancho" Lombardi

Hacia un cine

peruano de

coproducción

\section{Libia Villazana}

D esde la década de 1980, el cine latinoamericano se ha visto en la necesidad de sumarse a la práctica de la coproducción con Europa y Estados Unidos, como vía única para garantizar la financiación y mantener activas las producciones nacionales, convirtiéndose así en una norma para el cine de nuestros países. Una de las instituciones europeas que más éxito ha tenido en este tema es Ibermedia, creada en 1997.

El Programa Ibermedia consiste en un fondo que ofrece ayuda financiera mayoritariamente a la coproducción cinematográfica organizada entre los países iberoamericanos. La actividad que desempeña este organismo multilateral se ha convertido en la fuente principal para la financiación de nuestras producciones.

Francisco Lombardi es uno de los directores latinoamericanos que más ha trabajado en coproducción con España. Comienza el ejercicio de coproducir sus largometrajes con este país en 1988, con la película La boca del lobo, y ha continuado desde entonces en esta línea, incluyendo Mariposa negra (2005), su más reciente producción. De sus 14 largometrajes, 10 se han realizado en coproducción con España o han involucrado a este país de alguna manera. Esta reconocida trayectoria le ha merecido a Lombardi la obtención de frecuente ayuda económica de parte de Ibermedia.

En esta entrevista, Lombardi comparte con nosotros su extensa expe- 
riencia como cineasta y su relación con la tarea de coproducir. Nos señala los aspectos positivos y negativos de esta práctica. Finalmente, nos deja con la incógnita de conocer cuál es aquella película suya, a la que tanto cariño le tiene, que sufrió las restricciones de los coproductores extranjeros.

Libia Villazana: ¿Cuál fue tu motivación para realizar Grandes miradas, que luego se convierte en Mariposa negra?

Francisco Lombardi: Siempre es un poco difícil establecer con mucha precisión las motivaciones que, al menos en mi caso, me llevan a decidirme por una historia o por otra. A mí me gustó el personaje principal de la novela: Gabriela. Me pareció además que la película me permitía hacer una historia que podía tener una comunicación con un público más masivo. Tiene de thriller y, al mismo tiempo, es una película de personajes. A mí me gusta por encima de todo el cine de personajes; cuando logro encontrar una dimensión en un personaje que pueda arreglar o acercarnos a ciertas esencias de la condición humana. Cuando un personaje consigue ser representativo de algo o consigue abrirnos un poco una ventana sobre algo de la naturaleza humana. Y el personaje de Gabriela es una opción extrema en un momento del drama de una vida. Me interesó mucho también que, a partir de la adaptación, encontramos esta relación entre dos chicas, entre dos mujeres que inicialmente se repelen y que progresivamente se sienten funcionando casi al unísono; se establece un vínculo muy fuerte. Yo he trabajado poco con personajes femeninos. Mi cine es básicamente un cine de hombres y hacía cierto tiempo que tenía interés de acercarme más al mundo femenino. Esta es la primera vez que lo hago de una manera directa. He hecho alguna, como Maruja en el infierno, que es una película sobre una chica, pero yo me doy cuenta de que básicamente realizo películas con personajes masculinos; incluso se me ha acusado en algún momento de que soy un cineasta de películas masculinas. Mariposa negra es un primer acercamiento a ese mundo y el proyecto que estoy preparando para más adelante es también una película sobre dos chicas. Todo este acercamiento al mundo femenino me resulta un poco misterioso; me resulta atractivo por lo novedoso, por ser distinto.

- ¿Por qué se cambia el título Grandes miradas por el de Mariposa negra?

- Digamos que Grandes miradas, la novela, toma muchos personajes de un momento particular de la historia política del Perú y me imagino que la intención de Alonso Cueto, el autor, era ofrecer un panorama de ese periodo. Grandes miradas se ajusta bien a eso. La película en cambio está muy centrada en la historia del personaje de Gabriela, de esta chica obsesionada por la muerte de su pareja y por llevar 
adelante esta venganza personal; entonces el título Grandes miradas no se ajustaba muy bien a la línea que habíamos escogido en el desarrollo de la novela. Luego, en una de las escenas, a Giovanna Polarollo, la guionista, se le ocurrió el tema de las mariposas, que le daba una dimensión especial al personaje, que tiene algo de ingenuo y de puro. Giovanna creó la historia de la mariposa negra que anuncia la muerte; entonces sugerí que ese podría ser el título de la película, porque tiene un gran vínculo con la muerte, como otras de mis películas; en cierto modo es una metáfora de eso.

\section{- ¿Y ese vínculo con la muerte tiene} que ver con algún tipo de obsesión tuya con relación a la muerte?

- Ese es un tema que cada cierto tiempo intento elaborar, pero no tengo nada especial con el tema; sin embargo, en mis películas siempre, de alguna u otra forma, está presente. Me imagino que la muerte es uno de los grandes temas, así como el tema del amor es común en muchas películas o es uno de los grandes temas en general. En mi caso existe un conflicto grave, y ese conflicto, esa inquietud, ese drama interno, tiene relación con la muerte; entonces, lo expreso mucho en mis películas de maneras diferentes, dependiendo del momento. Hoy, por ejemplo, tengo una relación con la muerte mucho más sosegada de la que tenía antes. Inicialmente era una sensación de horror y de pánico, y aun cuando siempre, secretamente, queda debajo todo ese terror que tenemos los humanos de morir, me imagino que de tanto darle vueltas y de elaborar el tema, uno comienza a aceptarla. Esto es difícil porque, en cierto modo, lo que estaría sintiendo el ser humano iría contra las leyes de la naturaleza.

Yo me imagino que esa presencia más o menos continua de la muerte en mis películas tiene que ver con mis preocupaciones, mis divagaciones, mis terrores y mis procesos de vínculo con el tema.

- En cuanto a la temática de Mariposa negra, me parece que se acerca bastante a la de Ojos que no ven, tu pelicula anterior, por las referencias a la corrupción en tiempos de Fujimori.

- Casi todas mis películas están situadas en un contexto y en un espacio determinados, y ese espacio tiene un vínculo necesario con lo que está ocurriendo, en ese momento, en una determinada sociedad. No es un cine que se autodefina como cine político o social, pero está contextualizado siempre. Habrá personas a las cuales les parece que mi cine es político; a mí no me parece que lo sea, pero al estar centradas en un determinado entorno, sí me interesa mostrar cómo ese entorno condiciona, influye, marca a los personajes y las acciones de la historia que estoy contando. En el caso de la película Ojos que no ven, quería ser 
una especie de gran mirada al país, a la sociedad; contaba muchas historias de clases sociales diferentes, con personajes de distintas edades; era como hacer un microcosmos para llegar a entender cómo la corrupción había atravesado todo. Era una película mucho más social, a pesar de que eran pequeñas historias, tenía un contenido muy amplio. Mariposa negra, en cambio, es una película mucho más centrada en un personaje o en dos, Gabriela y Ángela, y cuenta una historia bastante particular; lo que hay alrededor de ella es el contexto donde todo ocurre, pero no es más que eso. Evidentemente, no habría ocurrido si el contexto hubiese sido distinto, pero la sensación de rabia y de justicia están dadas por una determinada situación. Ahora no es la situación lo que se está comentando o analizando, son las consecuencias de esta y las consecuencias específicas en un personaje concreto, que es Gabriela, de una gran pureza personal que expresa la alegría de vivir; una persona extremadamente positiva, que de pronto ve que toda su vida gira de una manera brusca, muy dolorosa, hacia la nada, y cómo ella intenta encontrarle una salida a la pérdida de ese universo. Esta es la historia de la película. Y desde la perspectiva de Ángela, que es la amiga, de alguna forma ella redime su vida, replantea sus cosas a partir de la experiencia que tiene con Gabriela. Entonces, también es la historia de una relación de dos.
- Como parte de la forma de financiar tu trabajo cinematográfico, alrededor del 85 por ciento de tus películas se ban becho en coproducción con España, desde La boca del lobo hasta Mariposa negra; sin embargo, en su mayoría, estas peliculas reflejan un balance muy bueno entre someter el guión a ciertos lineamientos que en muchos casos demandan las coproducciones y mantener tus bistorias centradas en temas locales. Dentro de esa extensa experiencia de coproducción, ¿has tenido en algún momento la necesidad de defender a un personaje o un pasaje dentro del guión, porque se te pidió que lo modificaras?, ¿cómo ba sido ese proceso de tener que someter el guión a las demandas de una coproducción, en la que tienes que cambiar elementos?

- En realidad, me parece que una de las razones por las cuales no he tenido la posibilidad de hacer una película por año, que es lo que a mí me gustaría, es en buena medida porque las historias que cuento están situadas en el Perú, y su capacidad de comercialización no es tan sencilla porque no son películas hechas para un mercado específico. No es que yo me esfuerce, por el hecho de que mis películas son una coproducción con España, en buscar una conexión con el gusto del mercado español. Esa es evidentemente una gran limitación que he tenido.

Como tú dices, yo siempre hago películas de historias que están muy contextualizadas en el medio que 
conozco, y eso ha hecho que durante alguna etapa haya tenido muy pocas posibilidades de producir; a pesar de que mis películas terminan exhibiéndose en distintos lugares, me ha costado mucho en los últimos años hacer cine. De mi película anterior a esta han transcurrido prácticamente tres años, que es demasiado tiempo si se toma en cuenta que tengo proyectos para realizar cine continuamente, que soy un director más o menos conocido y que, por lo tanto, en teoría tendría más posibilidades de producir; finalmente, intento hacer lo que me parece mejor.

En algún momento el problema principal fue la selección de los actores o el equipo técnico necesario para realizar una coprodución. En algún momento, que no voy a decir cuál, esto me ha perjudicado; es decir, han habido personajes que, quién sabe, hubieran resultado mejor con el actor que originalmente estaba previsto.

Luego, en el tema de hacer cambios en el guión, no he tenido que hacerlo; pude haber tenido discusiones por el montaje, la edición, la duración de las películas, pero, al final, trato de adaptarme. Primero, soy muy sincero y le digo al productor exactamente qué cosa es lo que viene. Sabía que Ojos que no ven era una película de tres horas y lo dije siempre. Es una película muy larga que cuenta seis historias; entonces, no me pueden pedir que al editarla dure dos horas porque no se va a poder. Claro, me costó mucho encontrar el dinero, que al final no encontra- mos. Tuvimos que hacer la película como una cooperativa, pero preferí eso a estar peleando en la edición.

En mi opinión, no es lo ideal hacer coproducciones. Yo creo que las películas, a contracorriente de lo que todo el mundo dice, deberían intentar hacerse en los países donde se producen, porque el cine más que la literatura, es uno de los grandes medios para poder expresar las culturas; es decir, las maneras de hablar, lo que uno ve, la imagen, el paisaje, la geografía, son cosas que tienen una vinculación tan cercana con el que las consume, con el espectador; el cine es tan realista en ese sentido que nada se le puede comparar en cuanto a identificar un lugar, una sociedad.

Entonces, estas mezclas de coproducciones que tienen que rodarse en diferentes lugares, tratando de conciliar distintos intereses, terminan despersonalizando las películas. Sin embargo, yo realizo coproducciones, esto quiere decir que, de alguna manera, en los países donde la falta de ayuda del Estado a la cultura, y en particular al cine, es tan grande como aquí en el Perú, no se pueden hacer películas solamente peruanas. Ahora estoy pensando que conforme se han ido abaratando un poco los costos, con cámaras que son cada vez más versátiles y que dan mejor calidad, tal vez con el tiempo termine haciendo un cine más pequeño, en el sentido de realizar producciones más pequeñas, que sean más personales y más lleva- 
deras. Creo que esto es lo que me gustaría hacer. Pero, mientras tanto, he hecho películas con una cierta carga industrial, con personal más o menos amplio y con una tecnología de relativa importancia; entonces, para poder hacer esto he trabajado en coproducción, y debo agradecer a aquellos que me ayudan a coproducir.

En el caso particular de Mariposa negra, se ha producido un fenómeno especialmente bueno para mí: me dejaron proponer los personajes que serían interpretados por actores españoles. Entonces, desde el guión he buscado tener, con lógica y sin ningún esfuerzo, lo que estaba pensando. En este caso, creo que va a ser la película que más armoniosamente se ha podido hacer en el tema de la coproducción.

- Es decir que cuando escribes un guión no estás pensando en cuál podría ser el personaje español, sino que eso lo ves después, en el momento de dialogar con el productor español.

- Varía mucho; depende del proyecto. Por ejemplo, si se trata de un libro, desde que lo lees sabes que tal personaje podría eventualmente ser interpretado por tal o cual persona. En un proyecto próximo que estoy trabajando, aunque todavía en el aire, hay un personaje que viene de fuera, es decir, la historia es así. Lo ideal es cuando la historia, por sí misma, te propone lo que debe ocurrir. Lo complicado es cuando la elección de uno de los intérpretes no te satisface. Eso me ocurrió con un intérprete español de una de mis películas que más quiero, que más aprecio; eso me pareció una pérdida.

- En lineas generales, en el tema de las coproducciones hay dos tendencias: una se centra en los beneficios que traen las coproducciones, como contar con mayor financiación, mayores posibilidades de realizar películas, y también la ganancia en cuanto a 'visibilidad', porque las películas realizadas en Latinoamérica, en coproducción con España o Francia, por ejemplo, son susceptibles de estrenos internacionales, de esta manera la presencia de los países latinoamericanos se acentúa afuera. Julio García Espinosa es uno de los directores y teóricos del cine defensores de esta teoría de la visibilidad. ${ }^{1}$ La otra tendencia se centra en lo que comenta el cineasta español José Luis Borau. ${ }^{2}$ Él dice, en cierto modo, lo que

1 ESPINOSA, Julio García. "Cine cubano: Un largo viaje hacia la luz". Conferencia ofrecida el 16 de febrero del 2005 en el Lecture Theatre 1, Cruciform Building, University College London, Reino Unido.

2 BORAU, José Luis, citado por RIX, Rob. "Co-productions and Common Cause: Spain and Latin America", en RIX, Rob y Roberto RODRIGUEZ-SAONA. Spanish Cinema: Calling the Shots. Trinity and All Saints, 1999, p. 118. 
comentabas, es decir que las coproducciones marcan la bistoria de las peliculas en el sentido de que ya no se bacen coproducciones para hacer peliculas, sino que estas se inventan para justificar una producción. Lo ideal, entonces, sería no hacer coproducciones.

- Pero qué hacer, por ejemplo, en el caso del proyecto en el que estoy pensando. Se trata de un personaje que se ha ido a vivir a Europa en un determinado momento y regresa al Perú por una situación $\mathrm{X}$, así es la historia, esa es una perfecta película para hacer una coproducción. Lo que quiero decir es que hay películas que se prestan de una manera natural para ser coproducidas y otras que se fuerzan para poderse financiar y deben hacerse en coproducción. Hay una manera que es la ideal, pero tampoco se puede decir que la otra está mal, porque, eventualmente, se consigue realizar películas coherentes, interesantes.

\section{- ¿Cuando escribes un guión para una} película, piensas en la audiencia?

- Sí, y sea que piense que va a interesarle a un público mayoritario o a muy poco público, esto no impide que siga escribiéndola. Esto no hace que acentúe el aspecto comercial o no comercial. Cada película tiene su historia. Cuando estábamos escribiendo Pantaleón..., nos divertíamos mucho y pensábamos, esta película probablemente va a tener mucho público. Así como cuando realizaba Sin compasión, una película muy encerrada, muy dura, era consciente de que se trataba de una película que iba a atraer poco público, pero a mí me parecía que tenía que hacerla, era lo que me había nacido. Pero sin duda soy consciente de que una película puede tener mayor capacidad de captar audiencia que otra. Cuando firmo un contrato como director de una película que sé que no va a ser rentable, no me preocupo de exigir mucho para mí, así lo he hecho y no me he equivocado. Cuando sé que una película tiene un potencial comercial muy grande - no porque la hayamos realizado con esa idea sino porque así era el proyecto- , como No se lo digas a nadie o Pantaleón y las visitadoras, entonces sí me preocupo mucho por el tenor del contrato, porque sé que la película va a generar mucho dinero, y me parece que si yo soy el realizador debo participar de los resultados.

Mi tendencia general ha sido siempre hacer películas que puedan ser comunicadas a un público; yo no hago, o no he hecho, un cine encerrado en sí mismo, que pretenda ser oscuro o que esté pensado en un público muy especializado. No me parece mal que se haga, pero no me planteo el cine así. Yo disfruto cuando una película tiene capacidad de comunicación. Nunca he sentido como una obligación hacer un cine que genere necesariamente una interacción con el espectador, o que lo haga pensar, o que lo sensibilice o lo mortifique, pero 
sí que haya un efecto, una vinculación entre el espectador y la película, sin que sea una obligación. Si uno hace películas en un país donde se necesitan 300 mil espectadores para acercarte a recuperar los costos, es bien iluso pensar que haciendo películas que van a llevar a las salas 15 mil personas puedas seguir haciendo cine; sencillamente no podrías hacer películas, salvo que te las plantees de otra manera, que es perfectamente legítimo. Por ejemplo, hacer cine con cámaras más livianas, con equipos más pequeños, que no pretenda captar una audiencia muy grande sino que respondan a lo que has querido hacer y que, de una u otra manera, has ido postergando porque no eran factibles de realizarse en los términos y con los equipos que se necesita para hacer cine.

A mí me interesa seguir haciendo cine y trato de que las películas tengan un público y puedan comunicarse. Algunas veces me he dado cuenta, desde el guión, de que la película tenía muchas dificultades de comunicación; entonces, traté de hacer una película económica, que no generara muchos gastos. Así, también me he equivocado, evidentemente. Ojos que no ven era una película popular, en mi opinión; una película que contaba muchas historias, breves, sencillas, algunas un poco más ambiguas, pero historias que se podían seguir $y$, sin embargo, la película tuvo una mala relación con el público. La fue a ver poca gente; en el Perú la vieron apenas 70 mil personas, que es poco en relación con otras películas mías. Y a pesar de que ganó algunos premios en festivales, es una película que no ha tenido el reconocimiento que probablemente merecía. Viendo hoy la película, después de un tiempo, observo que es una radiografía de un tema muy presente en el Perú: la corrupción. Es una película de un momento determinado, que consigue expresar, con mayor o menor capacidad de logro, una serie de historias que tocan un tema básico para entender lo que pasa en esta sociedad. Y eso está vivo, por eso creo que conforme pasen los años, esa película será una especie de exponente de lo que ocurrió; pienso que tiene un carácter histórico.

\section{- Sí, documental.}

- Sí, en cierto modo. Pero ha tenido poca suerte; el cine es así.

- Y la última pregunta. ¿Qué quisieras decirle al Perú que aún no le has dicho a través de tus películas, y qué quisieras decirle al resto del mundo que aún no has podido decirle o mostrar?

- En realidad, el tema no pasa por lo que uno quiera decir ni por lo que dice; pasa por ese lado misterioso que tiene el hecho de hacer una película o escribir un libro a partir de alguna motivación que no es muy clara, que en un determinado momento de la vida te impulsa a hacer algo. Entonces, lo que existe son películas un poco 
diferentes unas de otras o un poco parecidas, con algunos personajes más representativos de algo que en otras películas, que es lo que a mí me interesa. ¿De qué me he preocupado yo? De contar historias que tengan que ver con lo que yo conozco, que revelen, de una u otra forma, un entorno que está relativamente cerca o lejos de mí, pero que más o menos conozco, o preocupaciones por lo que ocurre alrededor de mí, algunas veces más vinculado a lo social, otras a lo individual. Pero lo que yo pretendería es que a través del conjunto de mis películas, se viera una parte de la naturaleza de la sociedad en la que me tocó vivir, y que cuando se vea ese conjunto se diga: "Mira, el Perú entre 1980 y el 2020". Es decir películas que expresan un cierto punto de vista, una visión de lo que ocurría en esos años. Si transcurre el tiempo y eso trasciende, creo que eso ya es valioso. 